\title{
JUEGOS DEL NARRADOR EN EL QUIJOTE
}

\section{EL NARRADOR}

Mi tema es la voz narradora en el Quijote, esa voz que, además de precederlas, se sitúa entre una y otra voz que en la obra habla en estilo directo ${ }^{1}$. Es, pues, la voz que presenta, identifica y va acompañando a las otras, incluyendo entre éstas las voces -en mi opinión, autónomasde los personajes narradores ${ }^{2}$. Es la voz cuya presencia recorre toda la obra, intermitentemente, de principio a fin, exceptuando, a mi ver, los dos prólogos. Como suele hacerse, la denomino simplemente "el Narrador". Se la ha llamado también "voz primordial", "narrador principal", "supranarrador", "narrador externo", "narrador extradiegético-heterodiegético", etc. José María Paz Gago ha dicho, acertadamente, que no se trata de un sujeto personal, sino de un sujeto textual; y nos recuerda también que el "cervantismo tradicional... lo ha ignorado"3.

1 Este trabajo es versión ampliada de uno que, con el mismo título, leí en el XVI Congreso de la AIH (París, julio de 2007) y después en una sesión ordinaria de la Academia Mexicana de la Lengua. He querido presentar aquí un esbozo de ciertos rasgos notables de la principal voz narradora en el Quijote, resumiendo un cúmulo de observaciones destinadas a un estudio más extenso.

2 En su admirable análisis narratológico, PAZ GAGO (véase la nota siguiente) considera que el narrador principal "cede la palabra" o "finge ceder la palabra" a los personajes (Semiótica, passim), a los cuales domina y controla. En este aspecto mi visión del Narrador difiere de la suya. Por lo demás, observo que en su Semiótica Paz Gago suele usar expresiones como "el narrador o los personajes", "el narrador y los personajes" y llega a decir que "las voces de los personajes tienen autonomía respecto a la del narrador" (p. 103 y cf. p. 108), una autonomía que les escatima en otros momentos. Disiento, en general, de su reiterada idea (coincidente con la de J.A. Parr) de que el narrador principal ejerce "control sobre la totalidad del texto narrativo" (p. 95, passim) y "asume y organiza el relato del Quijote, su configuración y estructuración" (p. 99): el gran organizador y controlador no puede ser, creo yo, sino el "autor empírico", o sea, Cervantes mismo.

3 José María PAZ GAGo, "El Quijote: narratología”, Anthropos, 1989, núm. 100, 43-48, y Semiótica del "Quijote". Teoría y práctica de la ficción narrativa, Rodopi, Ams- 
El hecho es que no existe, que yo sepa, una observación atenta y detenida de esa voz y sus características; Paz Gago, por ejemplo, sólo esboza algunas de ellas, como iremos viendo. El presente trabajo es un intento inicial de suplir esa laguna, de ver ciertas transformaciones de la voz narrativa, lo mismo que algunos de sus recursos y estrategias. No es mi intención asomarme a las voces de los personajes narradores, ni menos especular sobre si nuestra "voz primordial" es o refleja la de Cervantes mismo; bástenos saber que es uno de sus grandes logros artísticos. No es sólo una voz más en el múltiple universo verbal del Quijote: su peso es de tal magnitud, que me atrevería a llamarla la tercera voz protagonista, compañera, en otro nivel, de las de don Quijote y Sancho.

Nuestro Narrador hace cosas muy diversas: relata y describe en tono neutro, pero también valora, comenta, critica, se burla, y hasta hace chistes. Su actuación, si así podemos llamarla, va cambiando, se va moviendo, así como todo en el Quijote "se mueve".

\section{LA OMNISCIENCIA Y SUS RUPTURAS}

Quizá la más frecuente de sus transformaciones es aquella que lo hace pasar continuamente de la omnisciencia a la no omnisciencia y viceversa. El Narrador se ha encargado él mismo de recalcar su frecuente omnisciencia cuando, burlándose, elogia a Cide Hamete Benengeli porque "pinta los pensamientos, descubre las imaginaciones... los átomos del más curioso deseo manifiesta” (II, 40, pp. 949$950)^{4}$. En efecto, se adentra sin escrúpulos en lo que los personajes piensan, imaginan, sienten, recuerdan, "dicen entre sî", siguiendo en esto a los narradores tradicionales..

Pero a la vez nos encontramos con un continuo rompimiento de esa omnisciencia, desde el comienzo mismo de la novela . "Quieren decir que tenía el sobrenombre de 'Quijada' o 'Quesada'” (I, 1,

terdam-Atlanta, 1995. Véanse pp. 90-98 de la Semiótica, y su crítica del cervantismo y de las confusiones en que incurre por "el hecho de no reconocer la existencia de un narrador exterior" (p. 97). Sobre éste son fundamentales las pp. 98-108, con amplia utilización de la bibliografía, de la cual prescindo aquí. Para complementar esa bibliografía, véase María Stoopen, Los autores, el texto, los lectores en el "Quijote" de 1605, UNAM-Universidad de Guanajuato-Gobierno del Estado de Guanajuato, México, 2002, pp. 189-194.

4 Cito por la edición en dos volúmenes de Francisco Rico, Don Quijote de la Mancha, Instituto Cervantes-Crítica, Barcelona, 1998.

5 En varios pasajes de su Semiótica, Paz Gago califica de omnisciente a nuestro narrador. En cierto momento (p. 103) reconoce que "sabe manifestar inseguridad, flexibilidad y liberalidad para superar... la ...omnisciencia total”; pero no va más allá. 
pp. 36-37). El Narrador desconoce el nombre de su protagonista y sólo registra la insegura opinión de otros: "quieren decir que" 6 .

Son muchos y diversos los recursos que usa el Narrador cuando se pretende no omnisciente. Ahí están los varios "autores", anónimos o no, y sus divergentes interpretaciones. Ahí, las referencias a opiniones de sujetos impersonales no identificados: "y así se cree que fueron al fuego" (I, 7, p. 88)7; “ ¿No es bueno que dicen que se holgó don Lorenzo de verse alabar de don Quijote?” (II, 18, p. 779). Del caballero manchego "es opinión que muchos años fue enfermo de los riñones" (II, 18, p. 772).

Eso por una parte; por otra, las muchas expresiones que aluden a una cierta inseguridad que manifiesta el Narrador sobre lo que él mismo va relatando. No sólo cuando fluctúa entre varias posibilidades, sino en los frecuentísimos "parece ser que", "debía de", "sin duda”. Así, las hacas con las que ansía refocilarse Rocinante "a lo que pareció debian de tener más ganas de pacer que de ál” (I, 15, p. 160). El mancebito que va a la guerra lleva "un bulto o envoltorio, al parecer, de sus vestidos, que al parecer debian de ser los calzones o greguescos, y herreruelo y alguna camisa” (II, 24, p. 832): el Narrador mete los ojos en el envoltorio y nos dice lo que lleva dentro, y a la vez aparenta no estar seguro de lo que contiene.

Otra manera que tiene el Narrador para mostrar -o fingir- que no lo sabe todo es la reiterada fórmula "como después se supo" y sus variantes: "Después se supo que había jurado el duque que si a él no le lavaran como a don Quijote...” (II, 32, p. 894). Un pasaje especialmente interesante se da en el episodio de las bodas de Camacho. Basilio "tenía, preparada la sangre, según después se supo, de modo que no se helase" (II, 21, p. 806). Aquí el Narrador se revela primero tan engañado como la mayoría de los invitados: nos informa que Basilio quedó "bañado en su sangre y tendido en el suelo, de sus mismas armas traspasado" (II, 21, p. 803); pretende, pues, ser un simple testigo de los hechos presentes y desconocer sus causas y su desarrollo ulterior.

Quizá por eso mismo, el Narrador tiende a confirmar los sucesos a posteriori, con la fórmula "Así era la verdad", con la cual, por cierto, hace nuevamente gala de su omnisciencia. "«No oigo otra cosa -respondió Sancho- sino muchos balidos de ovejas y carneros». Y así era la verdad, porque ya llegaban cerca los dos rebaños" (I, 18, p. 193). Muchas veces, como en este caso, son los personajes los que relatan las cosas, y el Narrador llega después para darles el visto bueno.

6 Cf. “¿Alonso Quijano?”, en Margit Frenk, Del Siglo de Oro español, El Colegio de México, México, 2007, pp. 149-158.

7 En todas las citas del Quijote las cursivas son mías. 


\section{El NARRAdor Ve POR los ojos de los PERSONAJES}

En esta línea se encuentra uno de los rasgos notables de las intervenciones del Narrador, cuando se muestra omnisciente. Con enorme frecuencia, él no cuenta las cosas directamente, sino a través de las percepciones de sus personajes. No dice: * "por el mismo camino venían unos encamisados", sino: "vieron que por el mesmo camino que iban venían hacia ellos gran multitud de lumbres... vieron que las lumbres se iban acercando a ellos", etc. (I, 19, pp. 200-201) ${ }^{8}$. El recurso está por todos lados y tiene sus variaciones. "Vivaldo, que deseaba ver lo que los papeles decían, abrió luego el uno dellos y vio que tenía por título... y él, leyendo con voz clara, vio que así decía" (I, 13, p. 146). Esperaríamos: *“y él, leyendo con voz clara, dijo...”, pero no: el texto tiene que pasar primero por sus ojos ${ }^{9}$.

\section{El NARrador habla como sus PERSONAJES}

Con esa manera de narrar, que a menudo hace recaer en los personajes la experiencia directa de los hechos, se relaciona sin duda uno de los aspectos más fascinantes del Quijote, aspecto que suele adquirir un sesgo lúdico: usando el estilo indirecto libre, el Narrador adopta los modos de hablar de sus personajes y, con ello, su visión de las cosas. Así, en ciertos momentos usa la fabla de don Quijote, como cuando nos cuenta que, en Sierra Morena, el manchego "estaba determinado de no parecer ante su fermosura fasta que hobiese fecho fazañas que le ficiesen digno de su gracia" (I, 29, p. 334).

Del mismo modo, el Narrador podrá hablar del "vuelo de Clavileño" (II, 42, p. 967), cuando ha aclarado que no hubo tal vuelo, o de "la desmayada Altisidora", después de haber dicho que sólo "fingió desmayarse" (II, 46, p. 999); o puede terminar el capítulo II, 29 con: "este fin tuvo la aventura del encantado barco" (p. 869), y todos sabemos que sólo estaba encantado en la imaginación de don Quijote.

La voz irónica del Narrador resuena muy claramente en el epígrafe de ese mismo capítulo, que reza "De la famosa aventura del barco

\footnotetext{
8 Aunque de manera algo distinta, PAz GAGo aborda este fenómeno, al cual, empleando el término de Jost, denomina “ocularización”, en Semiótica, pp. 136-137.

9 Aquí entra también el hecho, tan curioso, de que los versos sólo se citan cuando un personaje los recuerda o cuando se les encuentra grabados en los árboles (II, 20, p. 798; II, 26, p. 292). El mancebito "iba cantando seguidillas" y "cuando llegaron a él, acababa de cantar una que el primo tomó de memoria, que dicen que decía: «A la guerra me lleva / mi necesidad... »" (II, 24, p. 833). Este pasaje es, además, buen ejemplo de las continuas alternancias entre la omnisciencia y su negación: el Narrador se introduce en la memoria del primo, pero luego añade ese "dicen que decía".
} 
encantado". Lo mismo ocurre en los epígrafes de otros capítulos ${ }^{10}$. Especialmente bonito es el del que precede al capítulo 18 de la Segunda parte: "De lo que sucedió a don Quijote en el castillo o casa del Caballero del Verde Gabán" (p. 771). En ningún momento afirma don Quijote que la casa de don Diego de Miranda es un castillo. Aquí el Narrador se nos quiere mostrar más quijotesco que el protagonista. Y todavía reincide dos veces; así, termina el capítulo diciendo: "y con buena licencia de la señora del castillo... se partieron" (p. 781).

Hay una evidente intención lúdica en esa adopción de la visión de don Quijote y en ese poner a prueba la perspicacia de los lectores: ¿hemos observado que sólo el malicioso Narrador, y no don Quijote, tergiversa la realidad?

\section{Mezcla de PERSPECTIVAS}

Pero más juguetón aún se muestra el Narrador cuando se da el lujo de mezclar la visión de don Quijote con lo que podemos llamar "su propia perspectiva". Esto ocurre de manera muy notable en el segundo capítulo de la Primera parte. Nos cuenta (p. 49) que don Quijote "fuese llegando a la venta que a él le parecía castillo"; luego, que "vio a las dos destraídas mozas que allí estaban, que a él le parecieron dos hermosas doncellas o dos graciosas damas". Muy poco después leemos que "llegó a la venta y a las damas"; no "la venta y las mozas", no "el castillo y las damas", sino una chistosa mezcla de ambas. Y enseguida irá alternando, durante varias páginas, a "las mozas" (pp. 50, 53), y "las traídas y llevadas" (p. 52) y "las rameras" (p. 54) con las "doncellas" (pp. 50, 52) y las "señoras" (p. 54).

Ya en el "castillo" de Juan Palomeque, dice el Narrador, entró "el barbero a quien don Quijote quitó el yelmo de Mambrino" (I, 44, p. 518), cuando, según su propia óptica, tenía que haber dicho "a quien don Quijote quitó la bacía". Y la tal bacía -el "baciyelmo" de Sancho- ha dado lugar antes a un graciosísimo juego del Narrador con los pronombres ${ }^{11}$, mezclando la perspectiva del amo con la de Sancho, que es también la del Narrador: don Quijote "mandó a

10 En la interesante sección de su Semiótica que dedica a los Epígrafes internos (op. cit., pp. 59-66) Paz GaGo, a la vez que subraya su "fuerte contenido lúdico", los atribuye explícitamente al "autor", y de él son, por supuesto. Conviene tomar en cuenta, sin embargo, que varios de ellos coinciden con la voz del Narrador en su adopción del punto de vista de don Quijote. Así, entre otros, el de I, 36, sobre la "brava y descomunal batalla" que el protagonista entabla con... "unos cueros de vino" (cf. PAZ GAGO, op. cit., pp. 62-63). Y los hay que coinciden con otras características de esa voz narrativa.

11 Juego respetado por casi todas las "ediciones básicas" de la obra, según la denominación de Rico. Véase ed. cit., t. 2, p. 719, notas 225-12 y 225-16. 
Sancho que alzase el yelmo, el cual, tomándola en las manos, dijo... Y dándosela a su amo, se la puso luego en la cabeza” (I, 21, p. 225). Como es Sancho el que toma lo que para él es bacía y se la da a su amo, la voz narradora emplea el femenino, identificándose así con él, incluso en "se la puso luego en la cabeza", acción obviamente realizada por don Quijote, para el cual el objeto era masculino.

Recordemos a este propósito lo que pasa en la Segunda parte con Ana Félix. Dice ella “-No soy turco de nación, ni moro, ni renegado. -¿Pues qué eres?, replicó el virrey. - Mujer cristiana, respondió el mancebo". El Narrador se empeña en que sea hombre: "dijo el mozo", "el lastimado mancebo" (II, 63, p. 1152), y sólo tres páginas después, reconoce finalmente que "el virrey, tierno y compasivo... se llegó a ella".

\section{El NARRADOR INDEPENDIENTE}

Frente a esa parcial y juguetona identificación del Narrador con lo que ven o imaginan sus personajes, la obra nos presenta también a un Narrador independiente, que tiene sus propias ideas sobre ellos y sobre sus actuaciones. Esta es otra de sus transformaciones. Abundan, como sabemos, los calificativos y comentarios valorativos que van tiñendo el relato, aun cuando éste parece más neutro e imparcial: los "el pobre caballero", "pensando en esos disparates", "su loca imaginación”, "aquellas sandeces", "el pobre escudero", "el mísero manteado”, etc., etc. Son a veces reflejo de lo que piensan los personajes, pero otras muchas los dice el Narrador por su cuenta y riesgo. He aquí unos ejemplos: "Le trujo a la imaginación una de las estrañas locuras que buenamente imaginarse pueden" (I, 16, p. 172). La frescura del lugar "convidaba a quererla gozar, no a las personas tan encantadas como don Quijote, sino a los tan advertidos y discretos como su escudero" (I, 49, p. 560). El Narrador se complace en juntar calificativos positivos y negativos y aseveraciones neutras con otras irónicas. De los que van a mantear a Sancho dice (I, 17, p. 184): "gente alegre, bienintencionada, maleante y juguetona”. Después de la terrible descripción de Maritornes en I, 16, p. 168, habla -en serio- de "la compasiva de Maritornes" (I, 17, p. 185).

\section{El NARRADOR, Visible}

Misma valoración, frecuentemente negativa, en los abundantes comentarios al margen. Finalizado el discurso de don Quijote sobre la Edad de Oro, la voz narrativa - que ha sido prácticamente neutra en los capítulos precedentes- nos sorprende con las siguientes palabras: "Toda esta larga arenga, que pudiera muy bien escusarse" y con 
"antojósele hacer aquel inútil razonamiento" (I, 11, p. 123). Al distanciarse del personaje, la voz del Narrador se hace más visible, más audible. Lo mismo, en muchos otros comentarios despectivos por el estilo y en el despiadado final de la aventura del barco encantado: "Volvieron a sus bestias, y a ser bestias" (II, 29, p. 874).

Hay momentos en los que el Narrador está en un tris de convertirse en personaje. Él pone y cambia apodos -a Cardenio, por ejemplo (I, 24), al Caballero de los Espejos (II, 12), a la "condesa Trifaldi” (II, 38)-; anticipa sucesos; se deleita en jugar con el tiempo. También crea suspenso, como en el graciosísimo pasaje en que don Quijote, habiendo vencido al Caballero de los Espejos, se inclinó sobre él y "vio... ¿Quién podrá decir lo que vio sin causar admiración, maravilla y espanto a los que lo oyeren? Vio, dice la historia, el rostro mesmo, la misma figura, el mesmo aspecto, la misma fisonomía, la mesma efigie, la perspectiva mesma del bachiller Sansón Carrasco" (II, 14, p. 744) ${ }^{12}$.

La presencia del Narrador es muy notable cuando juega con expresiones lexicalizadas: "don Quijote se acomodó al pie de un olmo y Sancho al de una haya, que estos tales árboles y otros sus semejantes siempre tienen pies y no manos" (II, 28, p. 867). "En estas pláticas se entretuvieron el caballero andante y el malandante escudero" (I, 49 , p. 560); los duques "tuvieron a gran ventura acoger en su castillo tal caballero andante y tal escudero andado" (II, 30, p. 879); "El uno durmiendo a sueño suelto y el otro velando a pensamientos desatados" (II, 70, p. 1193).

Le gusta al Narrador jugar con la polisemia: "No se curó el arriero destas razones (y fuera mejor que se curara, porque fuera curarse en salud)" (I, 3, p. 58); y le gusta contraponer al sentido figurado de una expresión su sentido literal: "Por sus pasos contados y por contar" (II, 29, p. 867).

Otro ejemplo de estos juegos, que me interesa destacar por un motivo diferente: después del maltrato final en la ínsula, Sancho "vistióse, en fin, y poco a poco, porque estaba molido y no podía ir mucho a mucho" (II, 53, p. 1064). Aun en un momento tan desastroso, el Narrador puede adoptar un tono burlón. Recordemos, a este propósito, la cruel ironía del Narrador justo antes de la brutal irrupción de los toros, que marca el comienzo del final de don Quijote. Dice: "la suerte, que sus cosas iba encaminando de mejor en mejor, ordenó que..." (II, 58 , p. 1105). Recordemos igualmente lo que dice el Narrador después de la derrota final del caballero: Sancho "temía si quedaría o no contrecho Rocinante o deslocado su amo [o sea, dislocado, descoyuntado], que no fuera poca ventura si deslocado quedara” (II, 64, p. 1161).

12 Es una lástima que muchas ediciones modernas -entre ellas, la por lo demás excelente edición conmemorativa de las Academias de la Lengua- pongan sólo la forma mismo en toda la obra. En el pasaje citado y en algunos otros (cito uno más adelante) se pierde así la graciosa alternancia mismo/mesmo. 
Cuando don Quijote está agonizando, “andaba la casa alborotada, pero, con todo, comía la sobrina, brindaba el ama y se regocijaba Sancho Panza, que esto de heredar algo borra o templa en el heredero la memoria de la pena que es razón que deje el muerto" (II, 74, p. 1221). Y para acabar de desdramatizar la escena: don Quijote "dio su espíritu, quiero decir que se murió”.

Aquí se ha cerrado el círculo: el "quiero decir" del Narrador empalma con su inicial "de cuyo nombre no quiero acordarme"13.

\section{EL YO DEL NARRADOR ${ }^{14}$}

Frecuente e interesante es la forma digo y el digo, pues, que. Suelen aparecer cuando la voz narradora desea aclarar algo. Y hay un caso particularmente divertido: don Quijote va "dándose priesa para llegar a una venta que al parecer una legua de allí se descubría. Digo que era venta porque don Quijote la llamó así, fuera del uso que tenía de llamar a todas las ventas castillos" (II, 59, pp. 1108-1109)15. Hace explícita de esta manera aquella identificación con el punto de vista de don Quijote que hemos visto antes, burlándose de su propia estrategia.

Pero es aún más notable la aparición del digo después del largo y sorprendente discurso en que el Narrador critica al eclesiástico de los duques y sus semejantes: "con ellos [entró] un grave eclesiástico destos que gobiernan las casas de los príncipes; destos que, como no nacen príncipes, no aciertan a enseñar cómo lo han de ser los que lo son; destos que...", y finalmente: "Destos tales digo que debía de ser el grave religioso" (II, 31, p. 884).

Al Narrador le gusta expresar sus opiniones con una exclamación seguida de la primera persona. Después de que don Quijote interrumpe a Cardenio y éste vuelve a enloquecer, exclama el Narrador: “¡Estraño caso, que así volvió por ella [por Madasima] como si verdaderamente fuera su verdadera y natural señora, tal le tenían sus descomulgados libros!" Y en seguida: "Digo, pues, que...”, y continúa la narración (I, 24, p. 269). Misma preferencia por las exclamaciones, en Cide Hamete ${ }^{16}$. En el episodio de los leones leemos:

13 Usa el quiero decir para explicar una expresión suya que podría pecar de sutil -"dio su espíritu"-, como ocurre también al comienzo del cap. II, 26, después de citar la Enei$d a$ : "Callaron todos, tirios y troyanos, quiero decir, pendientes estaban todos" (p. 846).

14 Cf. Paz Gago, op. cit., p. 100. Dejo de lado ahora el sorprendente capítulo 9 de la Primera parte con su Narrador transformado, por un instante, en personaje que habla en primera persona.

15 Antes de esto (II, 44, p. 984), hemos leído un pasaje análogo: "Afligióse en estremo el buen señor, y diera él por tener allí un adarme de seda verde una onza de plata, digo seda verde porque las medias eran verdes".

16 PAZ Gago señala este rasgo como característico de Cide Hamete (Semiótica, p. 93), sin notar que también el Narrador, en ciertos momentos, prorrumpe en 
Y es de saber que llegando a este paso el autor desta verdadera historia exclama y dice: “ $; O$ f fuerte y sobre todo encarecimiento animoso don Quijote...! ¿Con qué palabras contaré esta espantosa hazaña...? Tú a pie, tú solo, tú intrépido... Tus mismos hechos sean los que te alaben, valeroso manchego, que yo los dejo aquí en su punto, por faltarme palabras con que encarecerlos" (II, 17, pp. 765-766).

En el episodio de los puntos de las medias, "Aquí exclamó Benengeli y, escribiendo, dijo: «iOh, pobreza, pobreza!... Yo, aunque moro, sé que...»" (II, 44, p. 984).

Cide Hamete suele usar directamente el yo; el Narrador, en cambio, opta casi siempre por los verbos en primera persona (digo, quiero decir, lo que ahora diré, tengo para mí que $)^{17}$. En todo caso, son maneras de llamar la atención del lector sobre su presencia en el texto ${ }^{18}$. El ejemplo más extremo y el juego más portentoso es, por supuesto, el que se produce en el capítulo noveno de la Primera parte, donde el Narrador, transformándose por un momento en personaje y fingiéndose descubridor del manuscrito de Cide Hamete, habla todo el tiempo en primera persona. Es, dice Paz Gago, "como si el narrador se hubiese introducido en la historia, pasando del régimen extra-heterodiegético al régimen intra-homodiegético"19.

No es extraño que algunos de los momentos más lúdicos de la obra aparezcan en los pasajes de la Segunda parte en los que el Narrador alude y cita a Cide Hamete Benengeli y a su traductor. Recordemos el comienzo del capítulo II, 24, sobre la cueva de Montesinos: "Dice el que tradujo esta grande historia... que... en el margen dél estaban escritas de mano del mesmo Hamete estas mismas razones: «No me puedo dar a entender ni me puedo persuadir de que al valeroso don Quijote le pasase... y si esta aventura parece apócrifa, yo no tengo la culpa... Tú, lector..., juzga lo que te pareciere»" (II, 24, p. 829) ${ }^{20}$.

Este dirigirse al lector es, por cierto, otro rasgo notable que comparten Cide Hamete y su Narrador. En la Primera parte: "Y eran (si

exclamaciones. Quizá se trate en algunos casos de una identificación suya con el estilo del ficticio autor moro.

17 Una excepción, al principio de la obra (en I, 2, p. 48): discuten los autores sobre cuál fue la primera aventura, "pero lo que yo he podido averiguar en este caso y lo que he hallado escrito en los anales de la Mancha...". Sobre el uso de la primera persona por el Narrador habla extensamente PAz GAGO, art. cit., p. 46, y Semiótica, pp. 100 ss.

18 Véase lo que dice Paz Gago, Semiótica, pp. 102-107, sobre ciertas manifestaciones de la presencia del Narrador.

19 Semiótica, p. 101.

20 Cf. el comienzo del cap. 5: "Llegando a escribir el traductor desta historia este quinto capítulo, dice que le tiene por apócrifo, porque en él habla Sancho Panza con otro estilo del que se podía prometer de su corto ingenio... pero que no quiso dejar de traducirlo" (II, 5, p. 663). 
no lo has, joh lector!, por pesadumbre y enojo), seis mazos de batán” (I, 20, pp. 218-219). En la Segunda: "Deja, pues, lector amable, ir en paz y enhorabuena al buen Sancho, y espera dos fanegas de risa que te ha de causar el saber cómo se portó en su cargo" (II, 44, p. 982)21.

Pero el juego más sensacional se da al comienzo del capítulo 44: "Dicen que [¿quién dice?] en el propio original desta historia se lee que llegando Cide Hamete a escribir este capítulo no le tradujo su intérprete como él le había escrito, que fue un modo de queja que tuvo el moro de sí mismo..." (II, 44, p. 979) y cuenta la queja del moro. El obtuso comentario de Clemencín a este pasaje hace aún más cómico el deliberado y deleitoso galimatías del Narrador ${ }^{22}$.

Estas osadías de la voz narrativa se dan sobre todo en la Segunda parte del Quijote. Pero casi todos sus juegos, sus bromas, sus transformaciones, sus apariciones en primera persona, se dan por igual en las dos partes. Este narrador, único y múltiple del Quijote, omnisciente y no (o casi no) omnisciente, identificado y no identificado con sus personajes, cercano a ellos y a la vez distante; este narrador que finge ser objetivo, pero que continuamente se proyecta y se entromete en su relato23; este narrador, grave y también juguetón y graciosísimo, es sin duda una de las grandes creaciones cervantinas.

Margit Frenk Universidad Nacional Autónoma de México

${ }^{21}$ Sobre este importantísimo aspecto, véase también PAz GAGO, art. cit. y Semiótica, pp. 104, 105, 119-120, passim.

22 Comenta Clemencín: "Todo esto del principio del capítulo es una algarabía que no se entiende. Porque ¿cómo podía leer en el propio original... que no lo había traducido fielmente su intérprete? Ni ¿qué tiene que ver esto con la queja...?” (II, p. 979n.).

23 No estoy de acuerdo con la idea expuesta por mi amigo Avalle Arce, de que el Narrador del Quijote es "infidente", unreliable (cf. ahora Las novelas y sus narradores, Centro de Estudios Cervantinos, Alcalá, 2006). A mi ver, lo es sólo en muy contadas ocasiones, como cuando, al final de la obra (II, 74, pp. 1218-1219) afirma: "porque verdaderamente, como alguna vez se ha dicho [no se ha dicho], en tanto que don Quijote fue Alonso Quijano el Bueno a secas [y no lo «fue» sino desde un ratito antes], y en tanto que fue don Quijote de la Mancha, fue siempre de apacible condición y de agradable trato", cosa que tampoco corresponde a los hechos. Véase a este propósito mi “'Alonso Quijano?”. 